Evaluation of dsRNA delivery methods for targeting macrophage migration inhibitory factor MIF in RNAi-based aphid control

\title{
Liu, Shaoshuai
}

2021

Liu , S , Ladera-Carmona , M J , Poranen , M , van Bel , A J E , Kogel , K-H \& Imani , J 2021

, ' Evaluation of dsRNA delivery methods for targeting macrophage migration inhibitory factor MIF in RNAi-based aphid control ' , Journal of plant diseases and protection : scientific journal of the German Phytomedical Society (DPG) , vol. 128 , pp. 1201-1212 . https://doi.org/10.1007/s41348-021-0

http://hdl.handle.net/10138/334030

https://doi.org/10.1007/s41348-021-00464-9

cc_by

publishedVersion

Downloaded from Helda, University of Helsinki institutional repository.

This is an electronic reprint of the original article.

This reprint may differ from the original in pagination and typographic detail.

Please cite the original version. 


\title{
Evaluation of dsRNA delivery methods for targeting macrophage migration inhibitory factor MIF in RNAi-based aphid control
}

\author{
Shaoshuai Liu' ${ }^{1}$ Maria Jose Ladera-Carmona ${ }^{2} \cdot$ Minna M. Poranen ${ }^{3} \cdot$ Aart J. E. van Bel $^{2} \cdot$ Karl-Heinz Kogel$^{2}$ (D) \\ Jafargholi Imani
}

Received: 23 December 2020 / Accepted: 9 April 2021 / Published online: 3 May 2021

(c) The Author(s) 2021

\begin{abstract}
Macrophage migration inhibitory factors (MIFs) are multifunctional proteins regulating major processes in mammals, including activation of innate immune responses. In invertebrates, MIF proteins participate in the modulation of host immune responses when secreted by parasitic organisms, such as aphids. In this study, we assessed the possibility to use MIF genes as targets for RNA interference (RNAi)-based control of the grain aphid Sitobion avenae ( $\mathrm{Sa}$ ) on barley (Hordeum vulgare). When nymphs were fed on artificial diet containing double-stranded (ds)RNAs (SaMIF-dsRNAs) that target sequences of the three MIF genes SaMIF1, SaMIF2 and SaMIF3, they showed higher mortality rates and these rates correlated with reduced $M I F$ transcript levels as compared to the aphids feeding on artificial diet containing a control dsRNA ( $G F P$-dsRNA). Comparison of different feeding strategies showed that nymphs' survival was not altered when they fed from barley seedlings sprayed with naked SaMIF-dsRNAs, suggesting they did not effectively take up dsRNA from the sieve tubes of these plants. Furthermore, aphids' survival was also not affected when the nymphs fed on leaves supplied with dsRNA via basal cut ends of barley leaves. Consistent with this finding, the use of sieve tube-specific YFP-labeled Arabidopsis reporter lines confirmed that fluorescent $21 \mathrm{nt} d s \mathrm{NA}_{\mathrm{Cy} 3}$, when supplied via petioles or spraying, co-localized with xylem structures, but not with phloem tissue. Our results suggest that MIF genes are a potential target for insect control and also imply that application of naked dsRNA to plants for aphid control is inefficient. More efforts should be put into the development of effective dsRNA formulations.
\end{abstract}

Keywords Macrophage migration inhibitory factor (MIF) $\cdot$ dsRNA $\cdot$ Phloem $\cdot$ Sitobion avenae $\cdot$ Xylem

\section{Introduction}

Macrophage migration inhibitory factors (MIFs) are multifunctional proteins regulating major processes in mammals, including activation of innate immune responses (Mitchell

Karl-Heinz Kogel

Karl-Heinz.Kogel@agrar.uni-giessen.de

Shaoshuai Liu

Shaoshuai.Liu@agrar.uni-giessen.de

Maria Jose Ladera-Carmona

Maria.Ladera-Carmona@agrar.uni-giessen.de

Minna M. Poranen

minna.poranen@helsinki.fi

Aart J. E. van Bel

Aart.v.Bel@bot1.bio.uni-giessen.de

Jafargholi Imani

Jafargholi.Imani@agrar.uni-giessen.de and Bucala 2000). MIF proteins also play a role in innate immunity of invertebrates and participate in the modulation of host immune responses when secreted by parasitic organisms such as aphids (Rosani et al. 2019; Ghosh et al. 2020). A broad survey of the presence of MIF genes across

1 Present Address: National Key Facility for Crop Gene Resources and Genetic Improvement, Institute of Crop Science, Chinese Academy of Agricultural Sciences, Beijing 100081, China

2 Centre for BioSystems, Land Use and Nutrition, Institute of Phytopathology, Justus Liebig University, Heinrich-Buff-Ring 26, 35392 Giessen, Germany

3 Molecular and Integrative Biosciences Research Programme, Faculty of Biological and Environmental Sciences, University of Helsinki, Helsinki, Finland 
803 species of plants, fungi, protists, and animals identified them in all eukaryotes. MIFs seem to be essential and highly conserved in some kingdoms (e.g., plants), while they appear more dispensable in other kingdoms (e.g., in fungi) or present in several diverged variants (e.g., insects), suggesting potential neofunctionalizations within the protein superfamily (Michelet et al. 2019). MIFs were discovered in 1966 as a product of activated T cells that limited the random migration of macrophages in vitro (David 1966). Subsequently, it was shown that MIFs not only are involved in cell proliferation and apoptosis but play a vital role in the host response against parasitic infection (Calandra and Roger 2003) and vice versa in parasite virulence (Ghosh et al. 2020).

MIFs of aphids also are involved in the response to pathogens and mutualistic symbionts (Dubreuil et al. 2014). Multiple copies of $M I F$ genes were found in aphid genomes, including pea aphid (Acyrthosiphon pisum, $A p$ ) and green peach aphid (Myzus persicae, Mp) (Dubreuil et al. 2014). MIFs are secreted in aphid saliva during feeding, thereby inhibiting major plant immune responses and therefore are crucial to plant infestation (Naessens et al. 2015). Ectopic expression of MIFs in leaf tissues inhibited major plant immune responses, such as the expression of defense-related genes, callose deposition, and hypersensitive cell death. Functional complementation analyses showed that MIF1 is the key member of the MIF protein family that allows aphids to exploit their host plants.

Aphids are one of the largest groups of phloem-feeding pests, which can cause huge losses in agriculture and horticulture worldwide (Jaouannet et al. 2014; Pons et al. 2020). They colonize the leaves and stalks, and migrate later towards the ears and settle among the bracts and kernels in the milky-ripe stage of corn plants. A massive withdrawal of sieve tube components weakens the plant and eventually leads to a reduced overall yield. In most cases, aphids act as important vectors of viruses to spread plant disease ( $\mathrm{Ng}$ and Perry 2004; Will et al. 2007). More than 5000 aphid species have been described (The International Aphid Genomics 2010).

We investigated the possibility of using MIF genes as targets for RNAi-based insect control in plants. Several studies have shown that aphids are sensitive to double-stranded (ds) RNA (Jaubert-Possamai et al. 2007; Pitino et al. 2011) and therefore are amenable to RNAi strategies in crop protection (Christiaens et al. 2020; Liu et al. 2020). In 2015, we showed that dsRNA derived from the gene encoding salivary sheath protein (SHP), when expressed in barley, strongly reduced the survival of the grain aphid Sitobion avenae ( $\mathrm{Sa}$ ) (Abdellatef et al. 2015). Similar results were obtained when the green peach aphid was grown on transgenic Arabidopsis thaliana expressing dsRNA with homology to the MpCOO2 gene (Coleman et al. 2015). The C002 gene was first described by Mutti et al. (2008) and is predominantly expressed in the salivary glands of aphids.

The degree and the persistence of RNAi in aphids are strong as evidenced by the finding that target genes were also down-regulated in nymphs born from mothers exposed to dsRNA-producing transgenic plants. Notably, S. avenae and M. persicae aphids reared on transgenic barley (Abdellatef et al. 2015) or Arabidopsis (Coleman et al. 2015), expressing dsRNA against salivary protein components, even showed a decline in survival over several generations. These reports strongly support earlier proposals to use RNAi-based strategies for insect control (Price and Gatehouse 2008; Burand and Hunter 2013).

While transgenic strategies using dsRNA-expressing plants have proven successful in insect control, other strategies might also be applicable. Injection and ingestion of dsRNAs also can induce significant levels of gene silencing in insects (Tomoyasu and Denell 2004; Zhu et al. 2011). Thus, it also might be feasible to deliver dsRNA through foliar application (San Miguel and Scott 2016; Gogoi et al. 2017). The purpose of our study was to assess the potential of $M I F$ genes as a target for pest control by oral delivery of dsRNAs derived from gene sequences of three Sitobion avenae MIF genes. We also compared the efficiency of different dsRNA delivery strategies, including exposure of aphids to artificial diet versus leaf spray application and a sucrose-aid delivery in order to provide theoretical support for future application.

\section{Results}

\section{Prediction of MIF genes in Sitobion avenae (Sa)}

Genomic MIF sequences of evolutionarily distant species from hemipterans revealed a highly conserved structure (Dubreuil et al. 2014; Michelet et al. 2019). With the aim to deduce MIF gene sequences in $S a$ from currently available expressed sequence tags (ESTs) in public databases (https://www.ncbi.nlm.nih.gov/), we searched for MIF genes in insect genomes. Based on known peach aphid Myzus persicae and pea aphid Acyrthosiphon pisum sequence data, partial sequences of SaMIF1, SaMIF3, and SaMIF4 were predicted, amplified by PCR using degenerate primers (Table S1) and sequenced. Sequence alignment, which also included the already published SaMIF2 sequence (Dubreuil et al. 2014), confirmed that SaMIFs are highly conserved in aphids' evolutionary history (Fig. S1). The identified SaMIF sequences (Table S2) were cloned and used as a template for dsRNA production. 


\section{Detection of fluorescence-labeled dsRNA in aphids' midguts after feeding}

We conducted dsRNA feeding experiments to assess the effect of MIF gene silencing on aphid survival. Since the sucrose concentration in artificial diet is critical, we first tested the optimal concentration of sugar supply. We found that a concentration of $7.5 \%(\mathrm{w} / \mathrm{v})$ sucrose is optimal for the survival of $\mathrm{Sa}$ (Fig. S2). Next, we investigated the uptake of fluorescent-labeled dsRNA by $S a$ nymphs from artificial diet. To this end, SaMIF1-dsRNA (223 nt; Table S2) labeled with UTP-PEG ${ }_{5}$-AF488 during the dsRNA synthesis was added to the artificial diet at

\section{dsRNAAF488 feeding}
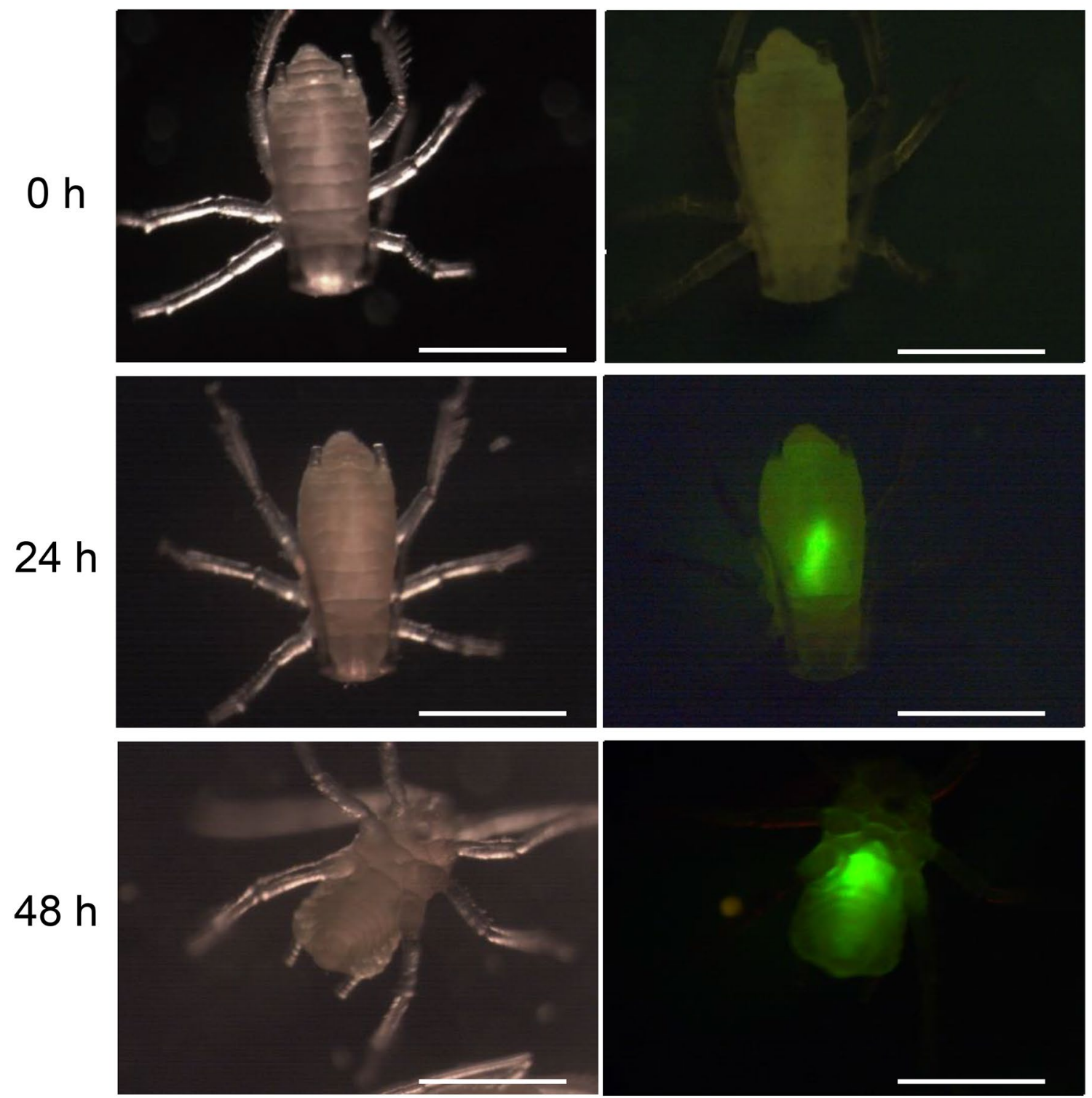

Bright field

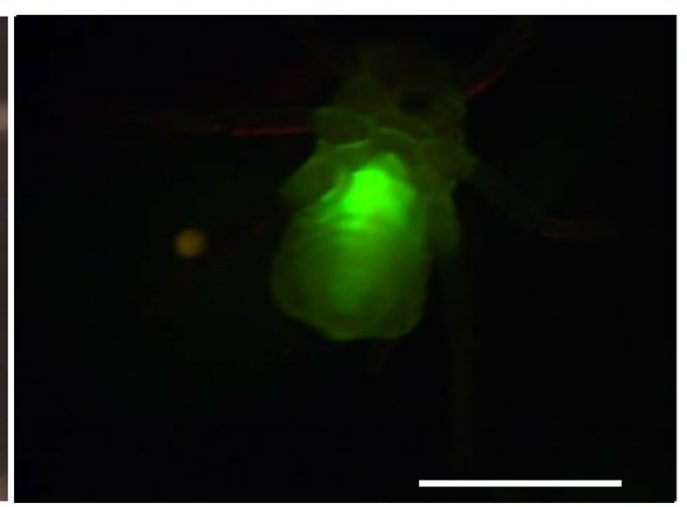

\section{Fluorescence \\ $\left(\lambda_{\mathrm{exc}} 494, \lambda_{\mathrm{em}} 515 \mathrm{~nm}\right)$}

Fig. 1 Uptake of fluorescence-labeled dsRNA from an artificial diet and its spreading inside Sitobion avenae. Pictures were taken at $0 \mathrm{~h}$, $24 \mathrm{~h}$ and $48 \mathrm{~h}$ after onset of feeding. The artificial diet contained $250 \mathrm{ng} / \mu \mathrm{L}$ SaMIF1-dsRNA ${ }_{\mathrm{A} 488}$. Fluorescence was detected in the insect gut. Left panels: stereo-microscopic analysis under bright field; right panels: fluorescence stereo microscopic analysis: excitation/ emission wavelength $(494 \mathrm{~nm} / 515 \mathrm{~nm})$, scale bars $=500 \mu \mathrm{m}$ 
a concentration of $250 \mathrm{ng} / \mu \mathrm{L}$. A fluorescent signal was observed in the midgut of $S a$ nymphs within $24 \mathrm{~h}$ and spread further into the body within $48 \mathrm{~h}$ (Fig. 1).

\section{The impact of different SaMIF-dsRNAs on aphids' survival}

Aphid MIFs are involved in the regulation of plant immune responses, but it remains largely unknown how the respective members of the MIF family contribute to this activity. In $M p$, mainly MIF1 functions as secreted salivary protein to suppress host immunity (Naessens et al. 2015). We investigated the effect of silencing different SaMIF genes on $S a$ 's survival. Since expression of MIF1, MIF2 and MIF3 are strongly induced after immune challenge in $M p$ (Dubreuil et al. 2014), we placed our focus on these genes. One-day-old $S a$ nymphs were fed with artificial diet containing dsRNAs directed against SaMIF1 (SaMIF1-dsRNA, 223 nt), SaMIF2 (SaMIF2-dsRNA, 323 nt), SaMIF3 (SaMIF3-dsRNA, $212 \mathrm{nt}$ ), and Green fluorescent protein (GFP-dsRNA, $476 \mathrm{nt}$ ) (see Table $\mathrm{S} 1$ ) at two different doses, $250 \mathrm{ng} / \mu \mathrm{L}$ and $125 \mathrm{ng} / \mu \mathrm{L}$. We found that survival rates of aphids treated with either SaMIFdsRNA versus GFP-dsRNA were significant reduced (Kaplan-Meier analysis and log-rank test, $p \leq 0.0001$ ) at day 4 of feeding with $250 \mathrm{ng} / \mu \mathrm{L}$ (Fig. 2a). Feeding with the lower concentration of SaMIF-dsRNAs $(125 \mathrm{ng} / \mu \mathrm{L})$ only resulted in a statistically significant lower survival rate after treatment with SaMIF1-dsRNA (Fig. 2b). This finding also confirms that beyond the anticipated function of MIFs as effector interacting with the plant's defense, MIFs have essential endogenous function in the aphid (Dubreuil et al. 2014).

\section{The impact of SaMIF-dsRNA on MIF target downregulation}

Next, we determined target gene silencing upon feeding aphids with the respective SaMIF-dsRNA (250 ng/ $\mu \mathrm{L})$ in artificial diet by $72 \mathrm{~h}$ of feeding using RT-qPCR. Consistent with the effects of dsRNA on aphids' survival, transcript levels of all three $S a M I F$ genes were reduced significantly (Student's $t$-test, $p<0.05$ ) (Fig. 3). These data further substantiate that the effect of SaMIF-dsRNAs on $S a$ is based on RNAi-mediated gene silencing.

\section{The impact of SaMIF-dsRNA mixtures on aphids' survival}

The above data indicate that $S a M I F 1$ plays a prominent role in the survival of aphids. To further assess $S a M I F 1$ as a target, we comparatively analyzed the effects of SaMIF1 silencing versus a triple gene silencing of all three $M I F$ genes on the survival of $S a$. Nymphs were treated with (1) SaMIF1dsRNA (187.5 $\mathrm{ng} / \mu \mathrm{L}),(2)$ a mixture of SaMIF1-dsRNA, SaMIF2-dsRNA, and SaMIF3-dsRNA (each at a concentration of $62.5 \mathrm{ng} / \mu \mathrm{L}$ in the artificial diet) and (3) GFP-dsRNA $(187.5 \mathrm{ng} / \mu \mathrm{L})$ as control. The relatively low concentration of individual SaMIF-dsRNAs in the mixture was chosen because we did not expect a measurable effect on aphid a

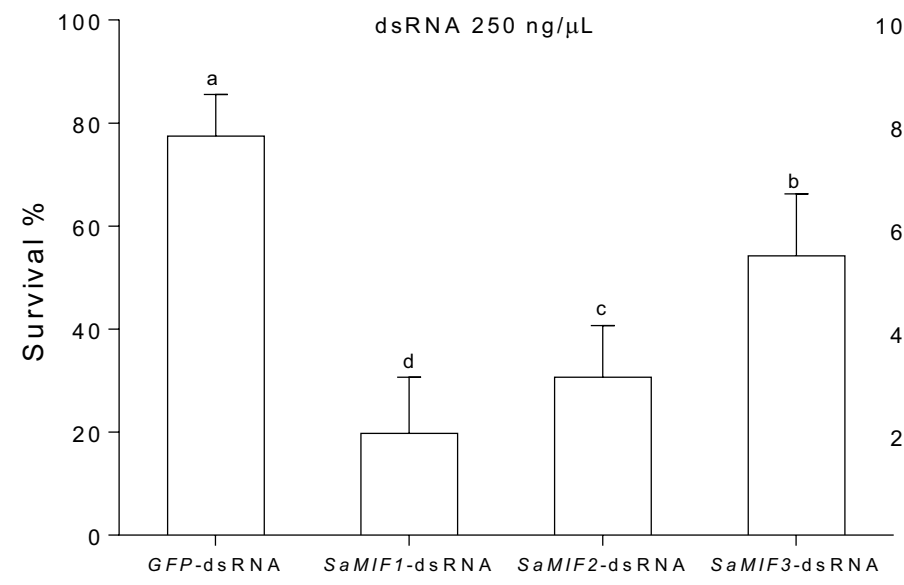

$\mathrm{b}$

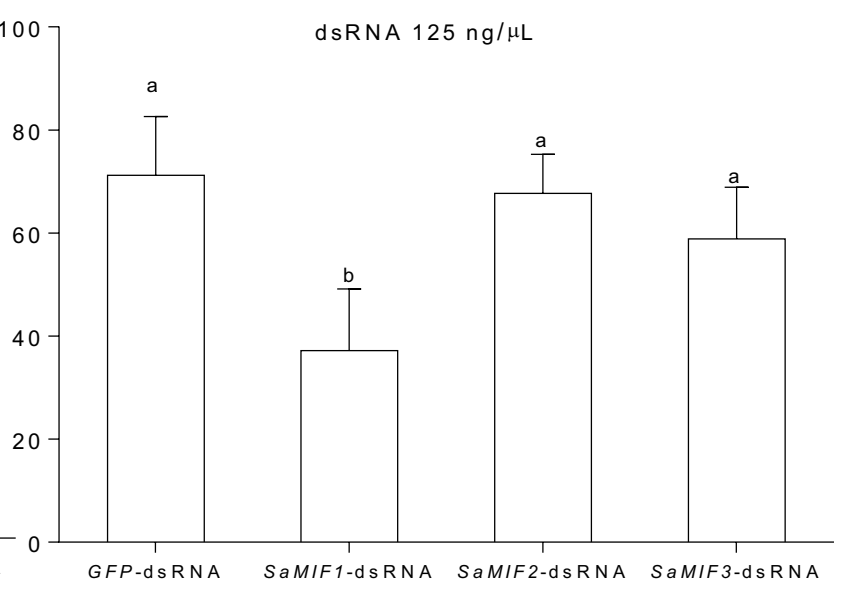

Fig. 2 Sitobion avenae survival rates after four days of feeding on artificial diet supplied with dsRNA present as percent of control (no dsRNA in the diet). SaMIF1-dsRNA, SaMIF2-dsRNA, and SaMIF3dsRNA were used with concentration of $250 \mathrm{ng} / \mu \mathrm{L}$ (a) and $125 \mathrm{ng} /$ $\mu \mathrm{L}$ (b) GFP-dsRNA was used as an additional control, since a tar- get for this dsRNA is lacking in aphids. Survival data were evaluated by Kaplan-Meier analysis and log-rank test based on three biological replicates. Bars represent means $( \pm S D)$ from three independent replicates. Different letters indicate significant differences at $p<0.001$ 
a

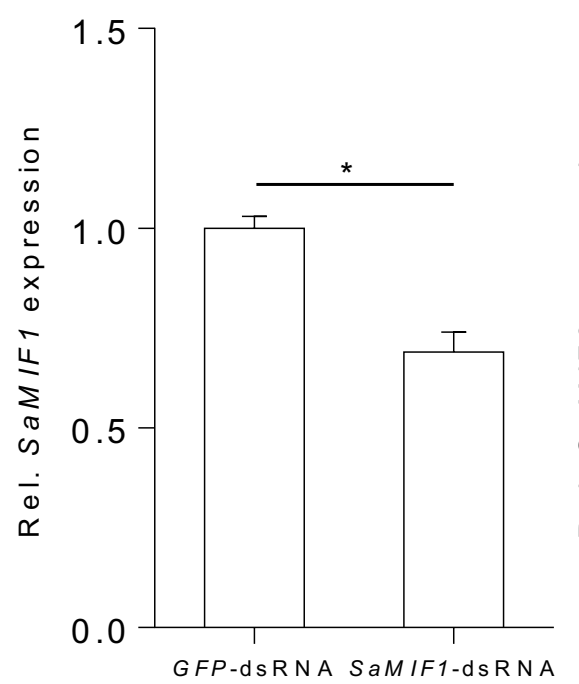

b

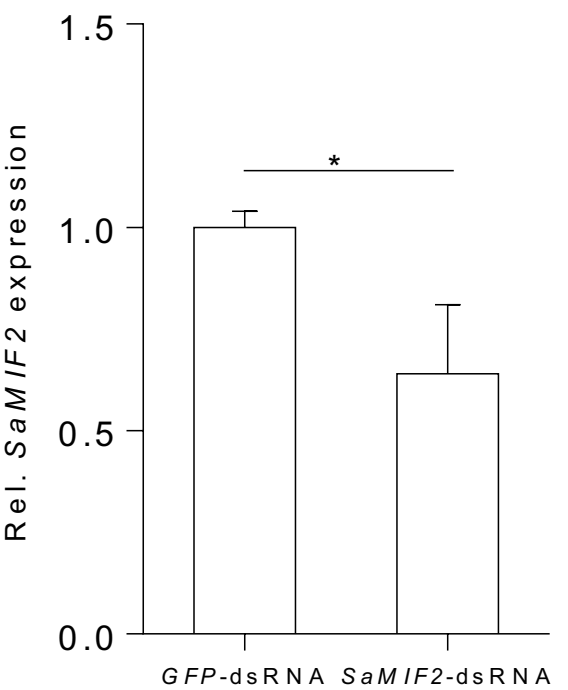

C

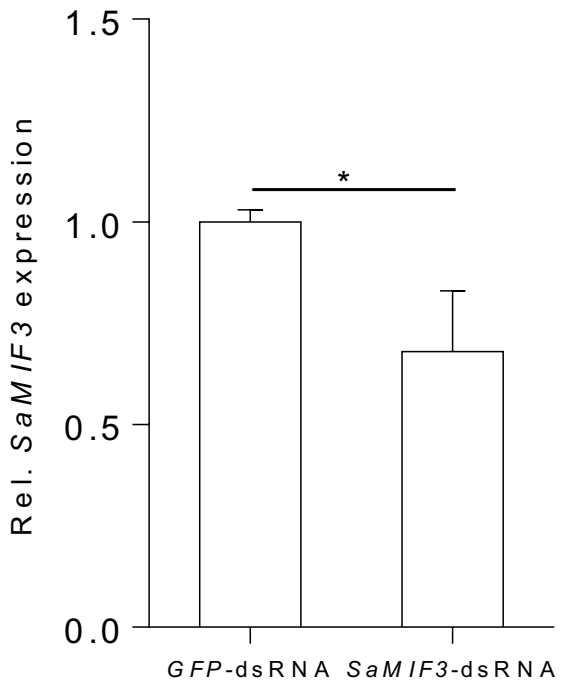

Fig. 3 Relative expression of target genes SaMIF1, SaMIF2 and SaMIF3 in Sitobion avenae fed on an artificial diet containing $250 \mathrm{ng} /$ $\mu \mathrm{L}$ of the respective $S a M I F$-dsRNA. RT-qPCR analysis data for a $S a M I F 1$, b SaMIF2 and c SaMIF3 were normalized to the aphid's

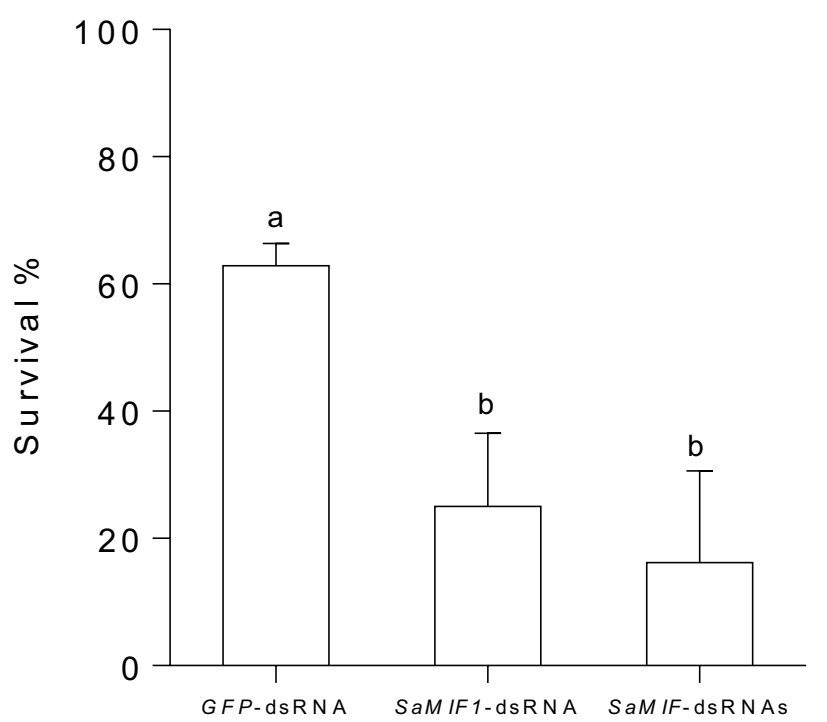

Fig. 4 Aphid survival after five days of feeding on artificial diet supplied with SaMIF1-dsRNA (187.5 ng/ $\mathrm{L})$, a mixture of SaMIF1dsRNA, SaMIF2-dsRNA and SaMIF3-dsRNA (each $62.5 \mathrm{ng} / \mu \mathrm{L}$ ) or $G F P$-dsRNA $(187.5 \mathrm{ng} / \mu \mathrm{L})$ as a control. Bars represent mean values $( \pm \mathrm{SD})$ of three biological replicates. Survival data were evaluated by Kaplan-Meier analysis and log-rank test. Different letters indicate significant differences at $p<0.0001$

survival when administered as single dsRNA doses (see Fig. 2). We found that $S a$ 's survival rates treated with either SaMIF1-dsRNA or the mixture of SaMIF-dsRNAs were significantly reduced (Kaplan-Meier analysis and log-rank
Ribosomal protein L27 (Rpl27) gene. GFP-dsRNA was used as a control. Bars represent means $( \pm S D)$ from two independent replicates. The asterisks indicate significant differences (Student's $t$-test; $p<0.05)$

test, $p \leq 0.0001$ ) after 5 days as compared with $G F P$-dsRNA treatments (Fig. 4). This suggests that the activity of single dsRNAs is not additive but might have a synergistic effect on the aphid mortality instead.

\section{SaMIF1-dsRNA spray application to barley seedlings had no effect on aphids' survival}

It has been controversially discussed as to whether application of exogenous dsRNA to plants results in its accumulation in the phloem tissue, which is a prerequisite for the RNAi-based control of phloem-feeding insects (Gogoi et al. 2017; Dalakouras et al. 2018). We investigated the possibility that direct application of SaMIF1-dsRNA to plants have an effect on $S a$ 's survival, when feeding from these plants. Therefore, three barley seedlings per pot were sprayed with $10 \mu \mathrm{g}$ SaMIF 1-dsRNA ( $500 \mu \mathrm{L}$ of a $20 \mathrm{ng} / \mu \mathrm{L}$ solution), and seedlings, which were infested $24 \mathrm{~h}$ later with 50 one-dayold $S a$ nymphs, kept in confined jars (Fig. S3a). Compared to $G F P$-dsRNA-treated control plants, we found no significant differences in the survival rates of aphids feeding on SaMIF1-dsRNA-treated plants (Fig. S3b) and controls. This finding implies that spray application to leaves does not result in the accumulation of sufficient amounts of dsRNA or small RNA duplexes derived from it in the sieve tubes and suggests that spray-treatment of naked, unformulated dsRNA probably does not meet the requirements of efficient crop protection. 


\section{Sucrose-aided dsRNA delivery to barley leaves had no effect on aphids' survival}

Next, alternative experimental designs were evaluated for simple and rapid screening of potential dsRNA targets for aphid control. Oligodeoxynucleotide (ODN)-directed gene silencing in barley is mediated by passive vascular feeding of ODN through cut leaves in sucrose solution via co-import of sucrose and negatively charged ODN molecules (Sun et al. 2005), suggesting that ODNs reached the leaf symplast and entered living cells. This report, together with accumulating evidence for xylem-to-phloem solute transport (van Bel 1990) and the presence of exo/endocytosis mechanisms in xylem vessels (Botha et al. 2008; Słupianek et al. 2019), prompted us to investigate whether the cut leaf delivery method could also be used to deliver dsRNA molecules to plant cells, including the phloem tissue. Detached leaves from two-week-old barley seedlings were dipped with the basal end into $1 \mathrm{~mL}$ of a solution of $200 \mathrm{mM}$ sucrose and $20 \mu \mathrm{g}$ SaMIF1-dsRNA (Fig. S4a), and kept in the dark for 24 h. As shown in Fig. 5a-c, dsRNA was taken up through the cut ends as revealed by the detection of fluorescence in upper segments of the detached leaves. In barley leaf cross sections, fluorescence was associated with the vascular bundle, especially the xylem parenchyma cells (Fig. 5d-g). Note that bigger xylem vessels lose their content during preparation of cross sections due to flushing with the fluid set free by the cut cells and thus do not show fluorescence.

Next, the survival of $S a$ on SaMIF1-dsRNA versus GFPdsRNA-treated detached barley leaves was recorded after seven days of infestation. Overall, there was no significant difference in the $S a$ 's survival rates on treated and control leaves (Fig. S4b). Consistent with this finding, no difference was found in the expression of the SaMIFl target gene in $S a$ fed on SaMIF1-dsRNA versus GFP-dsRNA treated leaves (Fig. S4c).
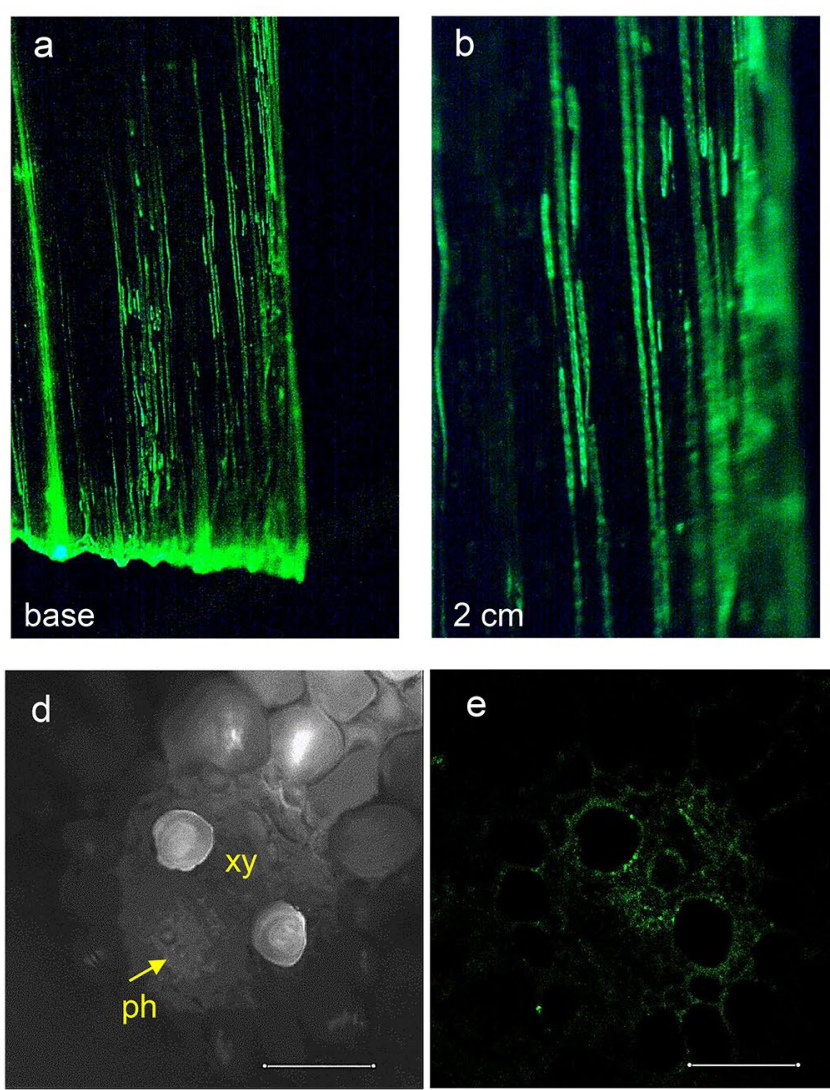

Bright field

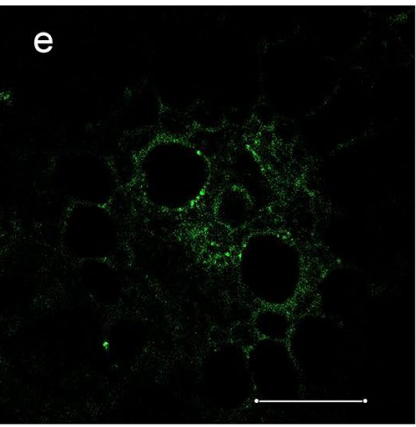

Fluorescence

AF488 $\lambda 494-515 \mathrm{~nm}$

Fig. 5 Confocal images of detached barley leaves having absorbed fluorescence-labeled SaMIF1-dsRNA ${ }_{\mathrm{A} 488}$ through cut basal ends. The leaf base was submerged in $1 \mathrm{~mL}$ of $200 \mathrm{mM}$ sucrose solution containing $20 \mu \mathrm{g}$ dsRNA. Surface views of a leaf base; $\mathbf{b}$ leaf segment $2 \mathrm{~cm}$ away from the base at $24 \mathrm{~h}$ after onset of soaking. $\mathrm{c}$ leaf segment $5 \mathrm{~cm}$ from the base $48 \mathrm{~h}$ after onset of soaking. $\mathbf{d}-\mathbf{g}$ leaf cross
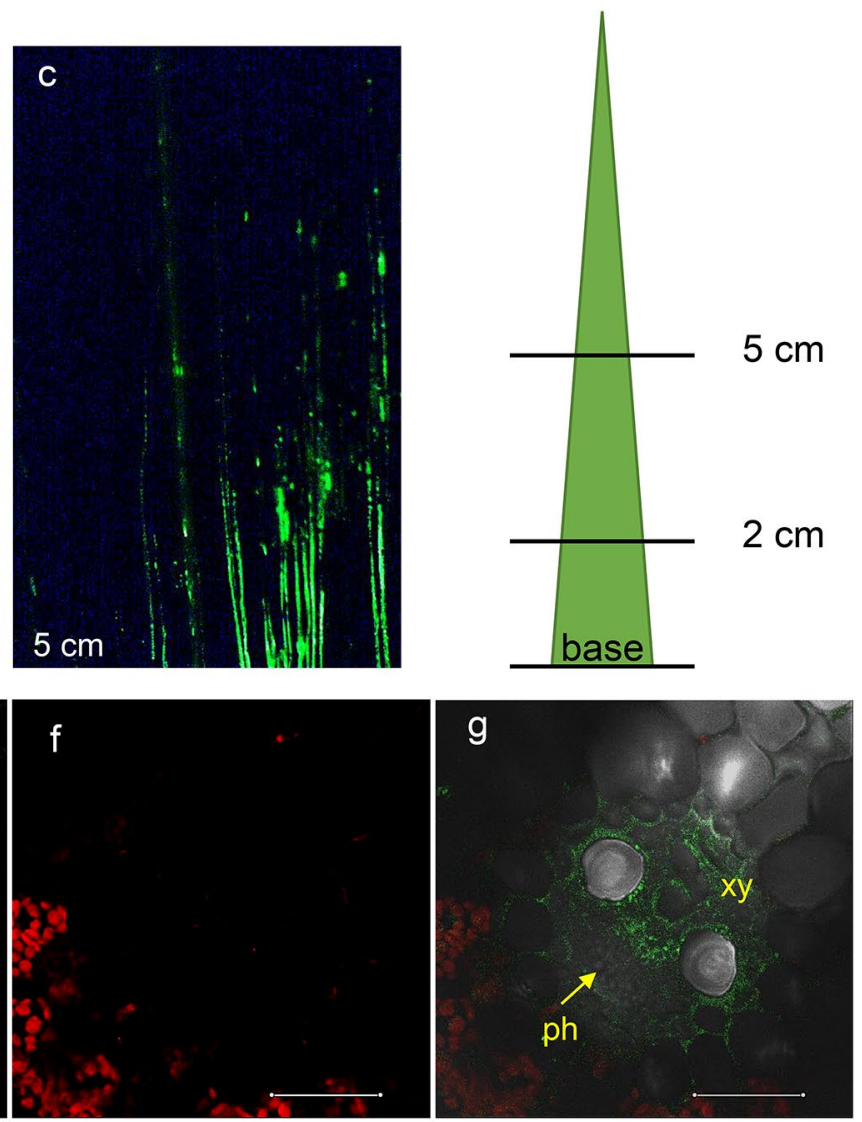

Fluorescence

AF633 $\lambda 631-642 \mathrm{~nm}$

section. ( $3 \mathrm{~cm}$ from the cutting), photographs taken at three days after onset of the SaMIF1-dsRNA ${ }_{\mathrm{A} 488}$ treatment. The green color represents the fluorescence $\left(\lambda_{\text {exc }} 494, \lambda_{\text {em }} 515 \mathrm{~nm}\right)$ of the Alexa Flour 488 (AF488) dye. The laser filter AF633 ( $\lambda_{\text {exc }} 631 \mathrm{~nm}, \lambda_{\mathrm{em}} 642 \mathrm{~nm}$ ) was used for the detection of red fluorescence of chloroplasts. xy, xylem; ph, phloem; bs, bundle sheath 
To further substantiate this finding, we conducted the sucrose-aided RNA uptake experiment with $S a S H P$-dsRNA (470 bp; see Table S2), which is known to target the SaSHP gene thereby strongly reducing the survival of the aphids on barley (Abdellatef et al. 2015). As shown in Fig. S4b, feeding on SaSHP-dsRNA treated leaves also had no effect on aphids' survival and expression of the $S H P$ gene in $S a$ was not affected (Fig. S4d).
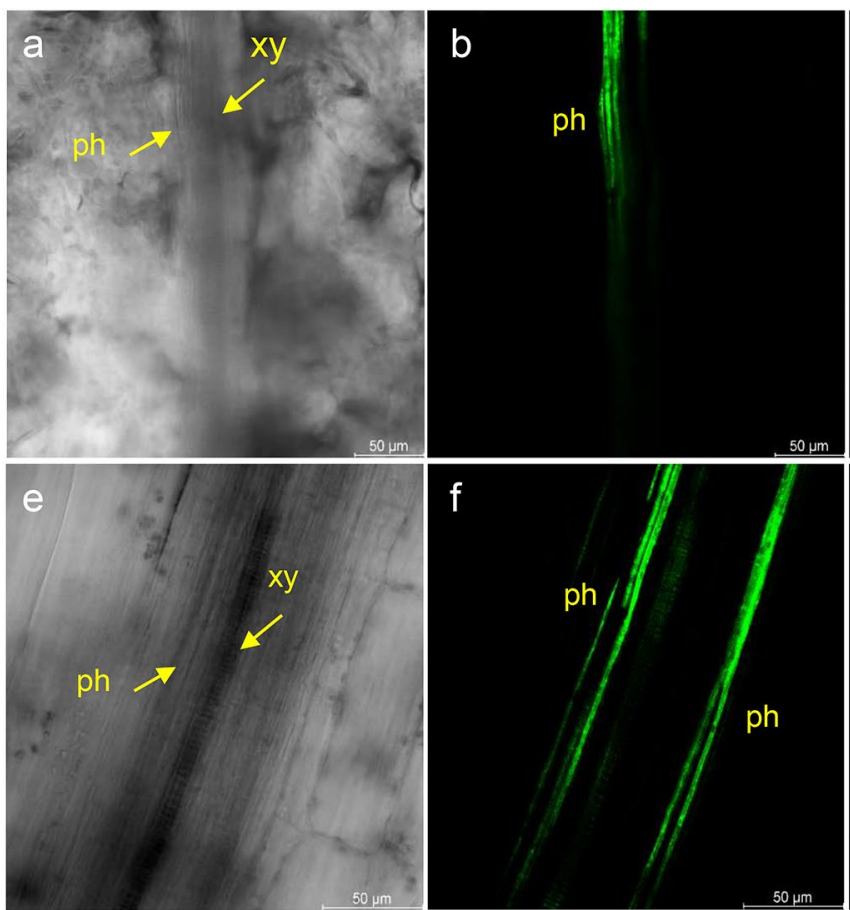

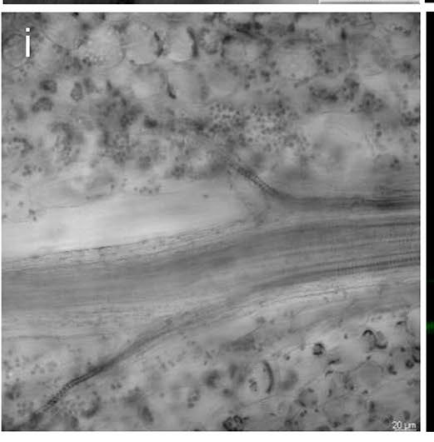

Bright field

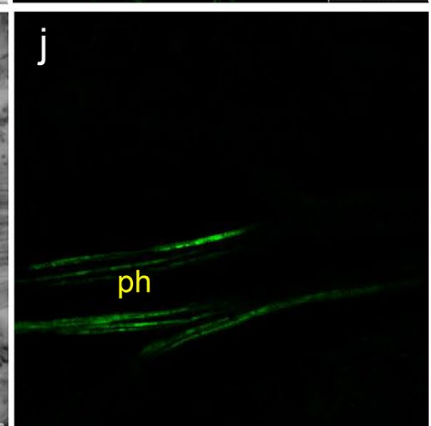

Fluorescence YFP (514 nm laser)
Fig. 6 Uptake of labeled dsRNA into Arabidopsis thaliana petioles and leaves. Confocal images of the reporter line $S U C 2:: Y F P$. a-h cut petiole ends were submerged for $24 \mathrm{~h}$ in nuclease-free water containing $20 \mu \mathrm{M}$ 21-nt siRNA $\mathrm{Cy}_{3}$ and cross sections were examined at the base $(\mathbf{a}-\mathbf{d})$ and in the middle of the petiole $(\mathbf{e}-\mathbf{h})$. i-l leaves were dropped with $21 \mathrm{nt}$ dsRNA $\mathrm{Cy}_{3}(20 \mu \mathrm{M})$ for $24 \mathrm{~h}$. Images were taken

\section{Petiole-mediated uptake of 21 nt dsRNA cyz $_{3}$ in Arabidopsis follows the xylem-route}

To further confirm the absence of microscopically detectable exchange of dsRNA between xylem and phloem vessels, when dsRNA is supplied via petioles, we used the Arabidopsis reporter line Arabidopsis thaliana SUC2::4xYFP, in which the promoter of the phloem-specific SUC2 is fused with Yellow fluorescent protein (YFP), allowing visualization of the sieve tubes (Marquès-Bueno et al. 2016). Leaves from thirty-two-day-old plants were inserted with the petioles in nuclease-free water containing fluorescent
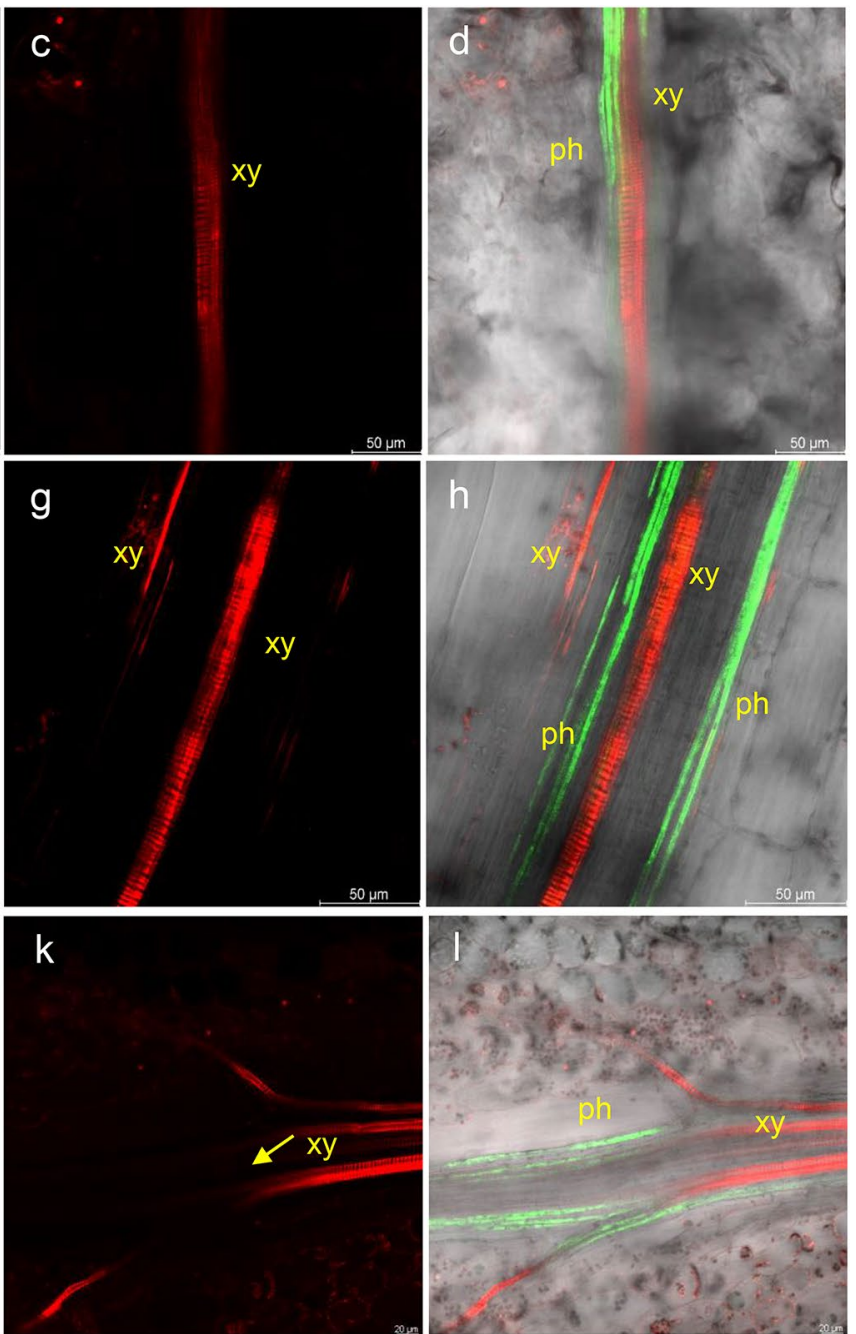

Fluorescence

Cy3 (561 nm laser)

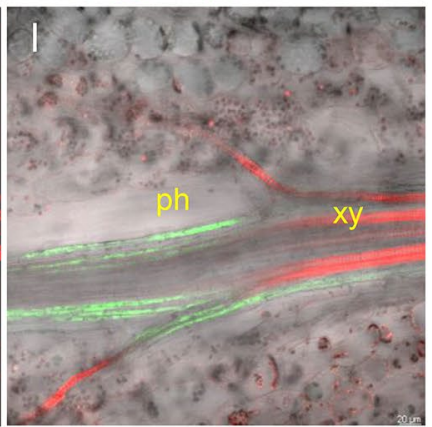

Merge

with a confocal microscope from different segments of the petiole. The red color, which is restricted to the xylem vessels, represents $\mathrm{Cy} 3$ fluorescence $\left(\lambda_{\mathrm{exc}} 561 \mathrm{~nm}, \lambda_{\mathrm{em}} 566-635 \mathrm{~nm}\right)$ and the green color represents the phloem-based YFP fluorescence $\left(\lambda_{\text {exc }} 514 \mathrm{~nm}, \lambda_{\mathrm{em}} 519-551\right.$ nm). xy, xylem; ph, phloem 
$21 \mathrm{nt}$ dsRNA $\mathrm{Cy}_{3}(20 \mu \mathrm{M})$. After $24 \mathrm{~h}$, confocal images were taken from different segments of the petioles. We found that dsRNA $\mathrm{Cy}_{3}$ was localized in the xylem, and its signal did not overlap with the YFP fluorescence of the phloem (Fig. 6a-h). Moreover, sucrose-aid uptake by petioles resulted in the same localization of $\mathrm{Cy} 3$ fluorescence in the xylem vessels (Fig. S5). This result is consistent with our finding that the survival of aphids is not negatively affected when they feed on leaves treated with dsRNA supplied via cut leaf ends. Thus, in contrast to reports showing that ODN can be introduced into plant cells via cut leaf ingestion, our data show that this method of introduction does not result in sufficient uptake of dsRNA or small RNA derivatives to affect aphids or be detected by fluorescence techniques.

\section{dsRNA delivery to leaves also follows the xylem route}

Finally, we used the Arabidopsis thaliana SUC2::4xYFP reporter line to visualize the uptake of fluorescence dsRNA from the leaf surface (Fig. 6i-1). Arabidopsis leaves were treated with four $1 \mu \mathrm{L}$ droplets containing $20 \mu \mathrm{M}$ dsRNA $\mathrm{Cy}_{3}$. After five days, confocal images were taken from different segments of the leaves. We found that dsRNA $\mathrm{Cy}_{3}$ was localized in the xylem, and its signal did not overlap with the YFP fluorescence of the phloem. This finding supports our notion that leaf-applied naked dsRNA does not reach the plant symplast and is therefore an inappropriate method for aphid control.

\section{Materials and methods}

\section{Plant material and aphids rearing}

Spring barley (Hordeum vulgare L.) cv. Golden Promise (GP) was used in all experiments. Arabidopsis thaliana (Col-0) SUC2::4xYFP lines were purchased from NASC (N2106107). Plants were grown under controlled conditions in a climate chamber at $22{ }^{\circ} \mathrm{C} / 18{ }^{\circ} \mathrm{C}$ day/night with $65 \%$ relative humidity, a $16 \mathrm{~h}$ photoperiod and a photon flux density of $240 \mu \mathrm{mol} \mathrm{m} \mathrm{m}^{-2} \mathrm{~s}^{-1}$. Arabidopsis seedlings were grown in vertical plates containing half-strength MS medium (Murashige and Skoog 1962), 0.5\% of sucrose and 0.7\% of agar. The grain aphid (Sitobion avenae, Sa) monoclonal population used in this study was reared on three-week-old GP plants in a climate chamber at $22{ }^{\circ} \mathrm{C}$ with a $16 \mathrm{~h}$ photoperiod and a photon flux density of $240 \mu \mathrm{mol} \mathrm{m}{ }^{-2} \mathrm{~s}^{-1}$. One-day-old fresh synchronized nymphs were used for the experiments (Abdellatef et al. 2015).

\section{RT- $q P C R$, transcript analysis}

RT-qPCR was performed with the Applied Biosystems QuantStudio 5 Real-Time PCR system. Amplifications were performed with SYBR $®$ green JumpStart Taq ReadyMix (Sigma-Aldrich). To quantify the target genes expression, the transcript was normalized with Ribosomal gene L27 (RPL27, NM_001126221.2) (Table S1) (Zhang et al. 2013). The program was performed with $95^{\circ} \mathrm{C}$ for $5 \mathrm{~min}, 40$ cycles $\left(95{ }^{\circ} \mathrm{C}\right.$ for $30 \mathrm{~s}, 57^{\circ} \mathrm{C}$ for $30 \mathrm{~s}, 72^{\circ} \mathrm{C}$ for $30 \mathrm{~s}$. Transcript levels of genes were determined via the $2^{-\Delta \Delta \mathrm{Ct}}$ method (Livak and Schmittgen 2001) by normalizing to the amount of reference gene transcript.

\section{dsRNA synthesis}

The Si-Fi software was used to select the donor sequences for the RNAi design (Luck et al. 2019). SaMIF genes were cloned into pGEM-T-easy vector, using the degenerate primers listed in Table S1, and the resulting plasmids were used as templates for the synthesis of dsRNA. Plasmids pGEM-Teasy-SHP and pGEM-T-easy-GFP contain respective SaSHP and GFP gene sequences (Table $\mathrm{S} 2$ ). The target sequences were amplified from the plasmid DNAs using primers containing $\mathrm{T} 7$ polymerase promotor or phi6 polymerase promoter sequences at their 5'-end (Table S1). SaMIF2-, $S a S H P$ - and $G F P$-dsRNAs were produced using a singletube transcription and replication reaction catalyzed by the T7 DNA-dependent RNA polymerase and the phi6 RNAdependent RNA polymerases (Aalto et al. 2007; Levanova and Poranen 2018). The produced dsRNAs were enriched using stepwise fractionation with $\mathrm{LiCl}$, followed by precipitation with sodium acetate and thorough washing of the resulting pellet with $70 \%$ ethanol. Alternatively, SaMIF- and GFP-dsRNAs were generated using MEGAscript T7 Transcription Kit (Thermo Fisher Scientific) following the manufacturer's protocol. The produced dsRNAs were resuspended in RNase-free milliQ-water and stored at $-20{ }^{\circ} \mathrm{C}$ prior use.

\section{Fluorescence labeling of dsRNA}

Fluorescence labeling of SaMIF1-dsRNA was performed using the HighYield T7 AF488 RNA Labeling Kit (Jena Bioscience, Germany) following the manufacturer's instruction. Labeled SaMIF1-dsRNA A488 $_{\text {-d }}$ was used for the uptake experiments. For uptake analysis of small RNA, $21 \mathrm{nt}$ $G A P D H$-dsRNA (provided in the kit) was labeled with $\mathrm{Cy}^{\mathrm{TM}} 3$ utilizing the Silencer ${ }^{\mathrm{TM}}$ siRNA Labeling kit (ThermoFisher) according to the manufacturer's instructions. 


\section{Feeding of aphids on dsRNA supplemented artificial diet}

The rearing method as described by Will et al. (2012) was used with minor modifications. The artificial diet $(50 \mathrm{mM}$ L-serine, $50 \mathrm{mM}$ L-methionine, and $50 \mathrm{mM}$ L-aspartic acid; $\mathrm{pH}$ 7.2) containing different sucrose concentrations was sealed between two layers of parafilm in a $2 \mathrm{~cm}$ diameter feeding tube, and one-day-old $S a$ nymphs were placed on the plates. The plates were covered with a feeding tube. The diet was prepared with RNase-free water. For dsRNA feeding experiments, the dsRNA was mixed with the artificial diet. Ten synchronized nymphs with five replicates for each sample were used. Nymphs were placed at $22{ }^{\circ} \mathrm{C}$ under $65 \%$ relative humidity, with a photoperiod of $16 \mathrm{~h}$ and a photon flux density of $125 \mu \mathrm{mol} \mathrm{m} \mathrm{m}^{-2} \mathrm{~s}^{-1}$.

\section{Application of dsRNA}

Three-week-old barley seedlings (each pot with three plants) were first sprayed with $0.02 \%$ Silwet-77, and 10 min later with $10 \mu \mathrm{g}$ dsRNA solved in $500 \mu \mathrm{l}$ deionized water. Controls were sprayed with $500 \mu \mathrm{L}$ of deionized water. After spraying, the plants were infested with $50 S a$ nymphs and stored in closed jars. Seven days later, the number of aphids was counted.

For treatment of Arabidopsis leaves, 19-day-old Arabidopsis SUC2::4xYFP seedlings grown in vertical plates were treated with $1 \mu \mathrm{L}$ drop of nuclease free-water containing $20 \mu \mathrm{M}$ dsRNA ${ }_{\mathrm{Cy} 3}$ at on the top of the leaf. Four leaves were treated. Confocal images were taken 5 days later.

\section{dsRNA delivery via the sucrose-aid method}

Ten-day-old barley seedlings were transferred to the dark for $12 \mathrm{~h}$. Leaves were detached and submerged with the basal end into $200 \mathrm{mM}$ sucrose solution containing $20 \mu \mathrm{g} / \mathrm{mL}$ dsRNA for $24 \mathrm{~h}$ in the dark. Subsequently, the submerged parts of the leaves were cut and the top segment transferred to agar plates and used for aphid infestation. Thirty-two-dayold Arabidopsis leaves were cut and inserted with the petiole in nuclease-free water containing $20 \mu \mathrm{M}$ dsRNA $\mathrm{Cy}_{3}$. For the sucrose-aid experiment, the solution was supplemented with $200 \mathrm{mM}$ sucrose.

\section{Microscopy}

Cross hand-cut sections of barley leaves were analyzed using a confocal laser-scanning microscopy (CLSM, Leica, TCS SP8, Germany). Green fluorescence of dsRNA ${ }_{\mathrm{A} 488}$ was detect by filter AF488 $\left(\lambda_{\mathrm{exc}} 494, \lambda_{\mathrm{em}} 515 \mathrm{~nm}\right)$. The laser filter AF633 ( $\lambda_{\text {exc }} 631 \mathrm{~nm}, \lambda_{\text {em }} 642 \mathrm{~nm}$ ) was used for the detection of red fluorescence of chloroplasts. Arabidopsis leaves were visualized with the CLSM microscope (previously described) for fluorescence YFP ( $\lambda_{\text {exc }} 514 \mathrm{~nm}, \lambda_{\text {em }} 519-551$ $\mathrm{nm})$ and $\mathrm{Cy} 3\left(\lambda_{\text {exc }} 561 \mathrm{~nm}, \lambda_{\mathrm{em}} 566-635 \mathrm{~nm}\right)$. YFP was excited with the $514 \mathrm{~nm}$ laser (detection 519-551 nm) and Cy3 with the $561 \mathrm{~nm}$ laser (detection 566-635 nm).

\section{Discussion}

We show here that members of the Macrophage migration inhibitor factor (MIF) protein family are necessary for the survival of the aphid Sitobion avenae. We found that $\mathrm{Sa}$ contains four MIF genes and that silencing of three of them, namely SaMIF1, SaMIF2 and SaMIF3, leads to reduced aphid survival on artificial diet. This corroborates findings that MIFs, apart from their roles in suppressing host immunity, also have an endogenous function in the aphid (Naessens et al. 2015). dsRNAs targeting individual SaMIF genes were effective at a concentration of $250 \mathrm{ng} / \mu \mathrm{L}$. At lower concentration $(125 \mathrm{ng} / \mu \mathrm{L})$, only dsRNA directed against the SaMIF1 transcript reduced target gene expression substantially, suggesting the possibility that SaMIF1 could be a potential target candidate for aphid control by RNAi.

Functionally redundant $M I F$ gene family members are widespread in eukaryotic genomes, which often hampers the analysis of gene families, due to functional redundancy (Jover-Gil et al. 2014; Martienssen and Irish 1999). For functional analysis, silencing of the entire set of paralogous genes at the same time is a straightforward approach. Simultaneous targeting of three out of the four known SaMIF genes using three SaMIF gene-specific dsRNAs caused a significant reduction in survival, when compared with the activity of a GFP-dsRNA that had no known target in $\mathrm{Sa}$ (Fig. 4). Interestingly, when applied in mixtures, SaMIFdsRNAs had a synergistic effect as they affected survival of $S a$ at a concentration that showed no effects upon single delivery. Overall in spite of these findings, our data suggest that SaMIF 1 is a candidate for aphid control and it is probably not required to consider the other SaMIF genes.

In our experiments, different dsRNA delivery strategies were investigated to test the efficiency of RNAi-mediated control of insects. Oral feeding on artificial diet containing SaMIF1-dsRNA showed the highest mortality rate (Fig. 2) and concomitant downregulation of SaMIF1 target transcripts (Fig. 3). In contrast, spraying SaMIF 1-dsRNA onto leaves had no effect on the survival rate of nymphs fed on these leaves (Fig. S3). This result can be explained by the fact that the SaMIF1-dsRNA applied to the leaves did not reach the sieve tubes in amounts sufficient to silence the SaMIF1 target gene, though it cannot be excluded that spraying leaves with higher concentration of dsRNA would have an effect on aphid survival. Uptake of dsRNA via the leaf surface has been controversially discussed. Gogoi et al. 
(2017) found that aphids take up, among others, a $588 \mathrm{bp}$ long dsRNA from tomato leaves. It should be noted, however, that the dsRNA was applied by gently rubbing the solution onto the upper side of tomato leaflets that were previously carborundum-dusted. Subsequently, the treated leaves were thoroughly washed with $0.05 \%$ Triton X-100 for five times in 3 min intervals. Moreover, dsRNA-mediated protection was obtained in tobacco against viral diseases, when leaves were spread with virus-specific dsRNA loaded on non-toxic, degradable, layered double hydroxide (LDH) clay nanosheets (Mitter et al. 2017). Once loaded on LDH, the dsRNA did not wash off, showed sustained release and could be detected on sprayed leaves even 30 days after application. Finally, it was recently reported that strong GFP transgene silencing was accomplished in tobacco and tomato by loading dsRNA into carbon dots (Schwartz et al. 2020). Chemical formulations not only enhance the uptake of RNA from leaves, but could also improve dsRNA penetration into an insect, as shown for a polymer/detergent formulation that improves RNAi-induced mortality in the soybean aphid Aphis glycines (Zheng et al. 2019). In the light of these reports, research should focus on dsRNA delivery strategies that might support more efficient use of RNAi-based plant protection.

Feeding of $S a$ on barley leaves immersed at the base in SaMIF1-dsRNA containing buffer also did not affect aphids' survival nor could we detect an effect on SaMIF1 target gene expression (Fig. S4). This setup was tested to evaluate an alternative experimental design for simple and rapid screening of potential dsRNA targets for aphid control. In agreement with a lack of effect on aphids, we could not detect fluorescence in phloem tissue when barley leaves had been submerged into fluorescence $S a M I F 1$-dsRNA 4488 solution. Instead, we detected fluorescence predominantly in the xylem parenchyma cells, mainly the contact cells (Fig. 5a-g). This is in agreement with earlier reports, where apical transport of exogenous dsRNA structurally is located within xylem structures (Dalakouras et al. 2018, 2020). While the latter reports and our investigation support the view that dsRNA application onto leaves and via petioles results in the accumulation of RNA in the xylem, some reports challenge this generalized view: (1) ODN-directed gene silencing in barley is mediated by passive vascular feeding of ODN through cut barley leaves using co-import of sucrose and negatively charged ODN molecules (Sun et al. 2005), resulting in ODN uptake into the leaf symplast and living cells. (2) The importance of the xylem-to-phloem pathway was underscored in a review that summarized work of the precedent two decades (van Bel 1990). Moreover, it is well accepted that exo/endocytosis processes are involved in the uptake of macromolecules from xylem tissue (Botha et al. 2008; Słupianek et al. 2019). (3) Turnip mosaic virus (TuMV) is a single-stranded RNA virus that can cause diseases in cruciferous plants. Viral RNA can move systemically through both phloem and xylem as membraneassociated complexes in plants (Wan et al. 2015).

Trafficking of vesicles carrying sRNAs has been observed between Arabidopsis and Botrytis cinerea (Cai et al. 2018; Šečić and Kogel 2021). Exosomes derived from Tetraspanin-GFP Arabidopsis line could be visualized as fluorescent dots, demonstrating that sRNA transfer occurs via exosomes. Trafficking of sRNA in vesicular bodies might explain why fluorescence appears in a punctate manner in traversal leaf section (Fig. 5a-c). As RNA transferred from one cell to another via exo/endocytosis would result in vesicles, a dotted fluorescence pattern would indeed occur. The fact that we could not detect dsRNA $_{\mathrm{A} 488}$ fluorescence in the barley phloem tissue led us to further experiments to substantiate a xylem-associated uptake of dsRNA. We repeated the RNA uptake experiments with the Arabidopsis SUC2::4xYFP reporter line, which is a more sensitive tool to distinguish between transport of solutes in xylem and phloem. When taken up by petioles, we detected $21 \mathrm{nt}$ dsRNA $\mathrm{Cy}_{3}$ exclusively in the Arabidopsis xylem, and its signal did not overlap with the YFP fluorescence of the phloem (Fig. 6a-h). This result further substantiates the previous report showing that dsRNA uptake and its acropetal transport follows mainly the apoplastic route via the xylem (Dalakouras et al. 2018). It also shows that a possible exchange of dsRNA from xylem-to-phloem is not efficient enough to be detected in our fluorescence microscopy experiment nor to silence genes from aphids feeding on the phloem at least at the concentrations used here. Nevertheless, soaking roots in dsRNA solution conferred protection in rice and maize against stem-borer ( $\mathrm{Li}$ et al. 2015), further showing the potential of the approach. We also used the Arabidopsis SUC2::4xYFP reporter line to follow the uptake of 21 nt dsRNA ${ }_{\mathrm{Cy} 3}$, upon dropping onto leaves (Fig. 6i-1). In agreement with the results from the barley spray experiments, we could detect fluorescence exclusively in the leaf xylem. While fluorescence imaging is sensitive and a well-accepted method, final proof of the absence of exogenously applied dsRNA in the symplast, e.g., in mesophyll cells and sieve tubes in missing. In particular, the observation that virus-specific dsRNA, when scattered on leaves, is effective in reducing viral infections suggests that dsRNA-possibly assisted by physical means such as formulations and gentle leaf wounding-can lead to symplastic uptake of dsRNA.

Supplementary Information The online version contains supplementary material available at https://doi.org/10.1007/s41348-021-00464-9.

Acknowledgements We thank Christina Birkenstock for technical assistance. The personnel of the HiLIFE Biocomplex unit at the University of Helsinki, a member of Instruct-ERIC Centre Finland, 
FINStruct, and Biocenter Finland, is also gratefully acknowledged. This work was funded in the cooperative German/French program by the Deutsche Forschungsgemeinschaft (DFG) and the Agence Nationale de la Recherche (ANR) to KHK (Ko 1208/25-1) as well as in the DFG program FOR5116 (KO 1208/30-1) to KHK and Academy of Finland (Grant \#331627) to MMP. SL was supported by the China Scholarship Council.

Authors' contributions SL, JI, MJL-C, AB and KHK wrote the manuscript; SL, JI, and K-HK designed the study; MMP prepared material for the experiments; SL and MJL-C conducted the experiments; K-HK, JI, MJL-C, SL and AB analyzed all data and drafted the figures. All authors commented and reviewed the final manuscript.

Funding Open Access funding enabled and organized by Projekt DEAL.

Data availability All data generated or analyzed during this study are included in this published article [and its supplementary information files].

\section{Declarations}

Conflict of interest The research described in the manuscript was not funded by private partners or industry. Author Shaoshuai Liu declares that he has no conflict of interest. Author Jafargholi Imani declares that he has no conflict of interest. Author Karl-Heinz Kogel declares that he has no conflict of interest. Author Minna Poranen declares that she has no conflict of interest. Author Maria Jose Ladera Carmona declares that she has no conflict of interest. Author Aart van Bel declares that he has no conflict of interest.

Consent for publication All authors declare consent of publication.

Ethics approval and consent to participate Approved by all authors.

Authorship principles All authors whose names appear on the submission.

(1) Made substantial contributions to the conception or design of the work; or the acquisition, analysis, or interpretation of data; or the creation of new software used in the work;

(2) Drafted the work or revised it critically for important intellectual content;

(3) approved the version to be published; and

(4) AGREE to be accountable for all aspects of the work in ensuring that questions related to the accuracy or integrity of any part of the work are appropriately investigated and resolved.

Open Access This article is licensed under a Creative Commons Attribution 4.0 International License, which permits use, sharing, adaptation, distribution and reproduction in any medium or format, as long as you give appropriate credit to the original author(s) and the source, provide a link to the Creative Commons licence, and indicate if changes were made. The images or other third party material in this article are included in the article's Creative Commons licence, unless indicated otherwise in a credit line to the material. If material is not included in the article's Creative Commons licence and your intended use is not permitted by statutory regulation or exceeds the permitted use, you will need to obtain permission directly from the copyright holder. To view a copy of this licence, visit http://creativecommons.org/licenses/by/4.0/.

\section{References}

Aalto AP, Sarin LP, van Dijk AA, Saarma M, Poranen MM, Arumäe U, Bamford DH (2007) Large-scale production of dsRNA for siRNA pools for RNA interference utilizing bacteriophage $\phi 6$ RNA-dependent RNA polymerase. RNA 13:422-429

Abdellatef E, Will T, Koch A, Imani J, Vilcinskas A, Kogel KH (2015) Silencing the expression of the salivary sheath protein causes transgenerational feeding suppression in the aphid Sitobion avenae. Plant Biotechnol J 13:849-857

Botha CEJ, Aoki N, Scofield GN, Liu L, Furbank RT, White RG (2008) A xylem sap retrieval pathway in rice leaf blades: evidence of a role for endocytosis? J Exp Bot 59(11):2945-2954

Burand JP, Hunter WB (2013) RNAi: future in insect management. J Invert Pathol 112:68-74

Cai Q, Qiao L, Wang M, He B, Lin FM, Palmquist J, Huang SD, Jin H (2018) Plants send small RNAs in extracellular vesicles to fungal pathogen to silence virulence genes. Science 360:1126

Calandra T, Roger T (2003) Macrophage migration inhibitory factor: a regulator of innate immunity. Nat Rev Immunol 3:791-800

Christiaens O, Niu J, Taning CNT (2020) RNAi in insects: a revolution in fundamental research and pest control applications. Insects 11:415

Coleman AD, Wouters RH, Mugford ST, Hogenhout SA (2015) Persistence and transgenerational effect of plant-mediated RNAi in aphids. J Exp Bot 66:541-548

Dalakouras A, Jarausch W, Buchholz G et al (2018) Delivery of hairpin RNAs and small RNAs into woody and herbaceous plants by trunk injection and petiole absorption. Front Plant Sci 9:1253

Dalakouras A, Wassenegger M, Dadami E, Ganopoulos I, Pappas ML, Papadopoulou K (2020) Genetically modified organism-free RNA interference: exogenous application of RNA molecules in plants. Plant Physiol 182:38-50

David JR (1966) Delayed hypersensitivity in vitro: its mediation by cell-free substances formed by lymphoid cell-antigen interaction. ProcNatlAcadSci USA 56:72-77

Dubreuil G, Deleury E, Crochard D, Simon J-C, Coustau C (2014) Diversification of MIF immune regulators in aphids: link with agonistic and antagonistic interactions. BMC Genom 15:762

Ghosh S, Padalia J, Ngobeni R et al (2020) Targeting parasite-produced macrophage migration inhibitory factor as an antivirulence strategy with antibiotic-antibody combination to reduce tissue damage. J Infect Dis 221:1185-1193

Gogoi A, Sarmah N, Kaldis A, Perdikis D, Voloudakis A (2017) Plant insects and mites uptake double-stranded RNA upon its exogenous application on tomato leaves. Planta 246(6):1233-1241

Jaouannet M, Rodriguez PA, Thorpe P et al (2014) Plant immunity in plant-aphid interactions. Front Plant Sci 5:663

Jaubert-Possamai S, Le Trionnaire G, Bonhomme J, Christophides GK, Rispe C, Tagu D (2007) Gene knockdown by RNAi in the pea aphid Acyrthosiphon pisum. BMC Biotechnol 7:63

Jover-Gil S, Paz-Ares J, Micol JL, Ponce MR (2014) Multi-gene silencing in Arabidopsis: a collection of artificial microRNAs targeting groups of paralogs encoding transcription factors. Plant $\mathbf{J}$ $80: 149-160$

Levanova A, Poranen MM (2018) Application of steric exclusion chromatography on monoliths for separation and purification of RNA molecules. J Chromatogr A 1574:50-59

Li H, Guan R, Guo H, Miao X (2015) New insights into an RNAi approach for plant defence against piercing-sucking and stemborer insect pests. Plant Cell Environ 38:2277-2285

Liu S, Jaouannet M, Dempsey DMA, Imani J, Coustau C, Kogel KH (2020) RNA-based technologies for insect control in plant production. BiotechnolAdv 39:107463 
Livak KJ, Schmittgen TD (2001) Analysis of relative gene expression data using real-time quantitative PCR and the 2(-Delta DeltaC(T)) Method. Methods 25:402-408

Luck S, Kreszies T, Strickert M, Schweizer P, Kuhlmann M, Douchkov D (2019) siRNA-finder (si-Fi) software for RNAi-target design and off-target prediction. Front Plant Sci 10:1023

Marquès-Bueno MDM, Morao AK, Cayrel A et al (2016) A versatile multisite gateway-compatible promoter and transgenic line collection for cell type-specific functional genomics in Arabidopsis. Plant J 85:320-333

Martienssen R, Irish V (1999) Copying out our ABCs: the role of gene redundancy in interpreting genetic hierarchies. Trends Genet 15:435-437

Michelet C, Danchin EGJ, Jaouannet M et al (2019) Cross-kingdom analysis of diversity, evolutionary history, and site selection within the eukaryotic macrophage migration inhibitory factor superfamily. Genes 10(10):740

Mitchell RA, Bucala R (2000) Tumor growth-promoting properties of macrophage migration inhibitory factor (MIF). Semin Cancer Biol 10:359-366

Mitter N, Worrall EA, Robinson KE et al (2017) Clay nanosheets for topical delivery of RNAi for sustained protection against plant viruses. Nat Plants 3:16207

Murashige T, Skoog F (1962) A revised medium for rapid growth and bioassays with tobacco tissue cultures. Physiol Plant 15:473-497

Mutti NS, Louis J, Pappan LK, Pappan K, Begum K et al (2008) A protein from the salivary glands of the pea aphid, Acyrthosiphon pisum, is essential in feeding on a host plant. ProcNatlAcadSci USA 105:9965-9969

Naessens E, Dubreuil G, Giordanengo P et al (2015) A secreted MIF cytokine enables aphid feeding and represses plant immune responses. CurrBiol 25:1898-1903

Ng JC, Perry KL (2004) Transmission of plant viruses by aphid vectors. Mol Plant Pathol 5:505-511

Pitino M, Coleman AD, Maffei ME, Ridout CJ, Hogenhout SA (2011) Silencing of aphid genes by dsRNA feeding from plants. PLoS ONE 6:e25709

Price DR, Gatehouse JA (2008) RNAi-mediated crop protection against insects. Trends Biotechnol 26:393-400

Pons C, Voß AC, Schweiger R, Müller C (2020) Effects of drought and mycorrhiza on wheat and aphid infestation. EcolEvol 10(19):10481-10491

Rosani U, Domeneghetti S, Gerdol M, Pallavicini A, Venier P (2019) Expansion and loss events characterized the occurrence of MIFlike genes in bivalves. Fish Shellfish Immunol 9:39-49

San Miguel K, Scott JG (2016) The next generation of insecticides: dsRNA is stable as a foliar-applied insecticide. Pest Manag Sci 72:801-809
Schwartz SH, Hendrix B, Hoffer P, Sanders RA, Zheng W (2020) Carbon dots for efficient small interfering RNA delivery and gene silencing in plants. Plant Physiol 184:647-657

Šečić E, Kogel KH (2021) Requirements for fungal uptake of dsRNA and gene silencing in RNAi-based crop protection strategies. Curr Opin Biotechnol

Słupianek A, Kasprowicz-Maluśki A, Myśkow E, Turzańska M, Sokołowska K (2019) Endocytosis acts as transport pathway in wood. New Phytol 222:1846-1861

Sun C, Höglund AS, Olsson H, Mangelsen E, Jansson C (2005) Antisense oligodeoxynucleotide inhibition as a potent strategy in plant biology: identification of SUSIBA2 as a transcriptional activator in plant sugar signalling. Plant J 44:128-138

The International Aphid Genomics C (2010) Genome sequence of the pea aphid Acyrthosiphon pisum. PLoSBiol 8:e1000313

Tomoyasu Y, Denell RE (2004) Larval RNAi in Tribolium (Coleoptera) for analyzing adult development. Dev Genes Evol 214:575-578

van Bel AJE (1990) Xylem-phloem exchange via the rays: the undervalued route of transport. J Exp Bot 41:631-644

Wan J, Cabanillas DG, Zheng H, Laliberte JF (2015) Turnip mosaic virus moves systemically through both phloem and xylem as membrane-associated complexes. Plant Physiol 167:1374-1388

Will T, Steckbauer K, Hardt M, Van Bel AJ (2012) Aphid gel saliva: sheath structure, protein composition and secretory dependence on stylet-tip milieu. PLoS ONE 7:e46903

Will T, Tjallingii WF, Thönnessen A, Van Bel AJ (2007) Molecular sabotage of plant defense by aphid saliva. ProcNatlAcadSci USA 104:10536-10541

Zhang M, Zhou Y, Wang H et al (2013) Identifying potential RNAi targets in grain aphid (Sitobion avenae F.) based on transcriptome profiling of its alimentary canal after feeding on wheat plants. BMC Genom 14:560

Zheng Y, Hu Y, Yan S (2019) A polymer/detergent formulation improves dsRNA penetration through the body wall and RNAiinduced mortality in the soybean aphid Aphis glycines. Pest ManagSci 75:1993-1999

Zhu F, Xu J, Palli R, Ferguson J, Palli SR (2011) Ingested RNA interference for managing the populations of the Colorado potato beetle, Leptinotarsa decemlineata. Pest ManagSci 67:175-182

Publisher's Note Springer Nature remains neutral with regard to jurisdictional claims in published maps and institutional affiliations. 